\title{
Barok Döneminde Avrupa ve Alman Literatüründe Çoban Edebiyatı
}

\author{
Meryem Nakiboğlu (D), Aydın
}

https://dx.doi.org/10.37583/diyalog.759409

$\ddot{o}_{z}$

Halkların millî kültürünü, yaşadıkları coğrafya ve inanç sistemi biçimlendirir. Çoban kültürü ve edebiyatı da millî kültürlere göre şekillenerek devam eder. Çoban edebiyatının kökeni mitolojiye dayanır. İtalya'da Rönesans döneminde şiirlerle başlar. İspanya'da pastoral romanla gelişimini sürdürür. Aynı dönemde İngiliz ve Fransız edebiyatına girer. Alman Edebiyatında ise Barok döneminde çeviriler yoluyla kazandırılır. Alman literatüründe bu alanda daha çok Barok, Aufklärung ve Rokoko dönemlerinde eserler verilmiştir. Masal, efsane, atasözü, şiir, roman, madrigal, opera, çoban oyunları türündeki eserleri kapsar. $\mathrm{Bu}$ çalışmanın amacı öncelikle çoban edebiyatının kaynağı, Avrupa'ya gelişi ve Alman Edebiyatına etkisini araştırmaktır. Araştırmada literatür tarama metodu kullanılacaktır.

Anahtar Sözcükler: Çoban, Mitoloji, Şiir, Efsane, Madrigal

\section{Abstract \\ Shepherd Literature in European and German Literature in the Baroque Period}

Communities' national cultures are formed by belief systems and the geography where they live. Shepherd culture and literature continue to exist by shaping according to the national cultures as well. The origin of shepherd literature is based on mythology. In Italy, the basis of literature begins with poetry in the renaissance revival. It continues with the development of pastoral fiction in Spain. In the same period, it enters English and French literature. Shepherd Literature entered German literature through translations in the Baroque period. In German literature, works were given mostly in this field during the Baroque, Enlightening and Rococo periods. It comprises belles-lettres such as fairy tale, myth, poetry, novel, madrigal, opera, and pastoral theatre. The purpose of this article is to investigate the genres of literature based on shepherd's culture. In this article, literature review will be used as methodology.

Keywords: Shepherd, Mythology, Poetry, Legend, Madrigal 


\section{EXTENDED ABSTRACT}

Shepherd literature shapes the national culture of people, the geography and belief system in which they live. Shepherd culture and literature continue to exist by shaping according to the national cultures as well. When the past adventure of the shepherd and its profession is examined, the culture is based on as far as human history. Shepherd profession based on the mythological sources which have been subject in the Bible. Shepherds are important in religions. The first domestication of animals that are beneficial to humans began in the 7000s and 8000s before Christ. These animals are cats, dogs, goats, sheep, cows, cattle and horses. The selection and raising factors of the shepherds who can take care of these animals and taking responsibilities, are important for human beings. In Europe, a rich shepherd culture has developed over the time and developed in interaction with each other and entered the literature in almost all nations on earth. The origin of the shepherd literature goes back to Greek mythology. In the Greek mythology, Pan is the guardian God of forests, fields, herds, and shepherds. Since he is not accepted from the great Gods such as Pan, Zeus, Poseidon, Demeter and,- Hephaistos, he lives in the remote mountainous region of Arkadia. For this reason, all literary genres based on shepherd's literature take place in the Arkadia region. Arkadia takes its name from the mythological character Arcas. Shepherd literature first started with poetry in Italy during the Renaissance period; and continued its development in Spain with the pastoral novels. Virgil, a member of the Arcadian poetry tradition, is considered one of the pioneers of pastoral poetry. With Italian humanist poets such as Francesco Petrarch and Giovanni Boccaccio, lyrical pastoral poetry developed in the 16. century. The Seven Books of Diana (1559) by the Portuguese writer Jorge de Montemayors is the first Spanish-written pastoral literary novel that combines verses and prose. It has been effective across Europe. Other important texts of the advanced Spanish tradition are Lope de Vegas'Arcadia and Miguel de Cervantes' La Galatea. In the La Galatea literary work, subject of love are covered under the guise of pastoral characters. In the United Kingdom, Sir Philpp Sydney's work Arcadia was published in 1581. Sydney takes the Spanish as an example in the Arcadia literary work. This work is translated into German by the Baroque poet Martin Opitz. In Italy, Barclay's work Argensis was published in 1621. The five-act L'Astrée by the novel summer bee Honoréd'Urfé in France has been translated into many languages by affecting the whole of Europe. In the same period, shepherd literature is included in English and French literature. In German Literature, translations entered during the Baroque era through Martin Opitz and Georg Philippe Hansdörffer. After that, German writers started to publish their first works. It is observed that more works were given in Germany during the Baroque, - Entlightening and Rococo periods. Novels about shepherds are called "Schäferroman" (Shepherd's novel) and,- poetry about shepherds are called "Schäferlyrik" (Shepherd Poetry). Philipp von Zezen Die's Adriatische Rosemund, Opitz's Schäfferey von der Nimfen Hercinie, Italian librettist Ottavio Rinuccini's shepherd opera Daphne which is composed by one of the leading German composers Heinrich Schütz, and exhibited in the first German opera (1627). The Baroque Period is the period when sectarian wars exist in Europe, 
people live in poverty and epidemics are wandering. Shepherd literature undertook a mission during these difficult times, to alleviate the suffering of people to a certain extent and to save them from troubles. Therefore, it is said to people of the period, "Live your life, make your day!", that was the message. Shepherd literature covers works such as prime, legend, proverb, poetry, novel, madrigal, opera and shepherd games. The aim of this study is primarily to investigate the source of the shepherd literature and also its arrival in Europe and its effects on German Literature. In this article, literature review will be used as methodology. 


\section{Giriş}

Çoban ve çobanlık mesleğinin geçmiş serüveni incelendiğinde insanlık tarihiyle paralellik gösterdiği görülür. Çoban/çobanlık hem mitolojik kaynaklarda hem de kutsal kitaplarda konu edilmiştir. İnsanoğlu geçmişten günümüze yaşadığı bölgelerde kendisi için yararlı olabilecek canlılardan faydalanmasını bilmiştir. $\mathrm{Bu}$ bağlamda beslenebilmesi için önce doğayı incelemiş, daha sonra da doğadaki yabani hayvanları avlamaya başlamıştır. Böylece av peşinde koşarak avladığı hayvanlarla beslenme ihtiyacını gidermiştir. İnsanlar zamanla hayvanları yakalayıp korunaklı bir yerde tutmanın daha güvenilir bir yol olduğunun farkına varmıştır (Şahin 2018: 107). Böylece yabani hayvanları evcilleştirme yoluna gitmişlerdir. $\mathrm{Bu}$ sebeple çobanlığın yabanî hayvanların evcilleştirilmesine paralel olarak ortaya çıktığını söylemek mümkündür.

Bilinen ilk hayvan evcilleştirmeleri M.Ö. 7-8 binli yıllarda başlamış, kedi, köpek, keçi, koyun, inek, sığır ve at gibi hayvanlar evcilleştirilmiştir. Zamanla oldukça zengin bir çoban kültürü oluşmuş ve birbirinden etkileşimle gelişerek hemen hemen yeryüzündeki tüm milletlerin literatürüne girmiştir.

Yunan mitolojisinde Pan, ormanların, tarlaların, hayvan sürülerinin ve çobanların koruyucu Tanrısıdır. Bu Tanrı, hiçbir zaman Antik Yunan'da 12 Olympos 'lu olarak kabul edilen büyük Tanrılardan ${ }^{2}$ biri olarak kabul görmemiştir. Tıpk1 Persephone, Hades ve Hekate gibi Pan da varlığının Olympos’ta hoş karşılanmadığını anlayarak hayatının sonuna kadar Arkadya ovalarında yaşamayı seçmiştir. Pan, daha çok Anadolu'nun batı bölgelerinde izlerine rastlanılan çoban Tanrılardan biridir. Pan'ın görüntüsü (ikonografisi) hayvan figürlerine benzer (Nilsson 1992: 235). Pan'ın keçi çobanları ile iletişim halinde olduğu, çobanları koruduğu bilinmektedir (Naumann 1983: 187). Yunan mitolojisinde olduğu gibi Sümerlerin de Çoban Tanrısı vardır. Gılgamış destanında koyun sürülerinin ve çobanların koruyucusu Çoban Tanrısı Dumuzi'dir. Dumuzi Çoban Tanrısı olduğu gibi aynı zamanda Bereket Tanrısıdır ve Mezopotamya bölgesinde yaşar.

Mitolojide olduğu gibi kutsal kitaplarda da çoban ve çobanlık mesleği konu edilmiştir. Özellikle semavi dinlerde çobanlığın korumacılık yönüne dikkat çekilerek insanlığa örnek meslek olarak gösterilmiştir. Almanlar Hazreti İsa'yı Gotteschäfer (Tanrının Çobanı) olarak adlandırırken Türkler çobanlık mesleğine kutsiyet atfetmişlerdir. Hazreti Musa ve Hazreti Muhammed de yaşamlarının bir bölümünde çobanlık yapmışlardır. Bu nedenle Anadolu'da çobanlık için "peygamber mesleği” denilmektedir (Nakiboğlu 2010b: 52).

Çoban kültürü Anadolu'da olduğu gibi Alman kültüründe de kendine özgü yaşam biçimini sürdürerek günümüze ulaşmıştır. Çoban figürleri ve sürü çobanlığı dünyanın hemen hemen her bölgesinde olduğu gibi Alman kültürünün de önemli unsurlarından biridir.

\footnotetext{
${ }^{2}$ Zeus, Gökyüzü Tanrısı. Poseidon, Denizlerin Tanrısı. Demeter, Doğa Tanrısı. Hephaistos, Demircilik Tanrısı. Ares, Savaş Tanrısı. Hermes, Habercilik Tanrısı. Apollon, Güneş Tanrısı. Dionisos, Şarap Tanrısı. Artemis,Okçuluk Tanrısı. Afrodit, Aşk Tanrısı. Athena, Bilgelik Tanrısı. Hera, Evlilik Tanrisidir.
} 
Çoban ve çobanlıkla ilgili çok sayıda efsane, menkıbe, atasözü, masal, şiir ve romanların varlığı dikkat çeker. Özellikle Barok döneminde daha fazla ilgi görmüş ve çeşitli türlerde eserler verilmiştir. Sonraki dönemlerde çoban edebiyatına ilgi her ne kadar azalsa da farklı türlerde eserler verilmeye devam etmiştir. Bu çalışmada öncelikle Çoban Edebiyatının çıkış kaynağına, ilk edebi eserlere, Alman kültüründe çobanlığın hangi edebi türlerde ele alındığına yer verilecektir. Edebi türlere değindikten sonra dönemlerin özelliklerine değinilerek pastoral türlerden örnekler verilecektir. Bu alanda ülkemizde yeterli araştırılma yapılmadığı dikkate alındığında makalenin önemli bir boşluğu dolduracağı düşünülmektedir.

\section{Alman Atasözleri, Efsane ve Masallarında Çoban Konusu}

Atasözleri, efsane ve masallar milletlerin kültürel zenginliği ve mirasıdır. Milli kültür ve inanç sistemi aynı zamanda insanların yaşam biçimini yansıtır. Her milletin kendine özgü kültürü olduğu gibi çoban kültürü de vardır. Bu bölümde çobanları konu edinen Alman atasözü, efsane ve masallarından örnekler verilecektir.

Geçmişten günümüze ulaşmış kısa ve özlü öğütler veren, toplum tarafindan benimsenmiş sözler olan atasözleri milletler için çok önemlidir. Çobanlarla ilgili Alman atasözlerinden birkaç örneği şu şekilde verebiliriz: "Schäfer und Schinder sind Geschwisterkinder" (Çoban ve cefa kardeş çocuklarıdır). Bu atasözünde çobanlık mesleğinin ne denli zor bir meslek olduğuna dikkat çekilmiştir. Der "Schäfer ist verdächtigt, der beim Wolfe Gevattersteht" (Çoban vaftiz babasının yanındaki kurtlardan bile şüphelenir). $\mathrm{Bu}$ atasözüyle çobanın sürüsüne zarar gelebileceği endişesiyle dikkatli ve şüpheci olması gerektiği vurgulanmıştır. "Jeder Schäfer lobt seine Keule” (Her çoban kendi çobandeğneğini över). Bu atasözünde çobanın savunma aracı çobandeğneğini benimsenmesi ve çoban için hayati önemi anlatılmıştır. "Kein Müller hat Wasser und kein Schäfer Weidegenug” (Ne değirmende su ne de otlakta yeterince çoban var). Bu atasözü ortada hiçbir şeyin olmadığına, maddi yokluğa, yaşanılan mekândaki güvensizliğe dikkat çeker. "Regenbogen am Morgen macht dem Schäfer Sorgen; Regenbogen am Abend ist dem Schäferlabend" (Sabah gökkuşağı çobanı endişelendirir, akşam gökkuşağı canlandırır). Bu atasözüyle gelecek endişesine dikkat çekilmiştir. Sabah çoban için yeni bir başlangıçtır. Ancak, yeni günün ne getireceği belli değildir. Akşam olduğunda çoban görevini başarıyla tamamlayarak tüm endişelerden arınmıştır. "Zu Lichtmassen hat der Schäfer lieber den Wolfals die Sonne im Stall” (Çoban kurtlara rağmen sürüyü güven içinde otlatmak için meradaki az ışı̆̆ı ahırdaki güneşe tercih eder). Bu atasözüyle çobanın tehlike arzeden durumlarda sürüsünün yanında olmayı tercih ettiği vurgulanmıştır (Wander 1873: 1146). Tüm bu atasözleri çoban/çobanlık konusunda Almanların kültürel zenginliğini ve inanç sistemini gösterir.

Halk edebiyatının köklü anlatım türlerinden olan efsaneler gerçeküstü olmalarına rağmen, gerçekten yaşanmış gibi kuşaktan kuşağa aktarılan öykülerdir. Pek fazla inandırıcı özelliği olmamasına rağmen bünyesinde bulundurduğu toplumların 
geçmişleriyle ilgili milli değerlerini, yaşam biçimlerini ve kültürel varlıklarını yansıtması bakımından önemlidir.

$\mathrm{Bu}$ öykülerin birçoğu kahramanca işler yapmış kişilerle ilgilidir. Efsanelerde insanlık, dürüstlük, cesaret, fedakârlık, cömertlik, iyilikseverlik, Tanrı'nın kudretine iman etme gibi ahlaki davranışlar, milli ve manevî değerler yüceltilir. Bulundukları mekân, coğrafya, dağ, taş, göl, ova, orman gibi varlıklar ile insan arasında sıcak ve yumuşak bir ilişki kurulur. Bunlar zamanla milletler için milli değerler haline gelir (Nakiboğlu 2010a: 773).

Grimm Kardeşlerin derlemesi olan Alman Efsaneleri'nde de çobanları konu edinmiş efsaneler mevcuttur. Bunlardan biri 316. efsane "Schäfer und der Alte aus dem Berg" (Çoban ve Dağdan Gelen Yaşlı Adam) adlı efsanedir. Bir diğeri ise 44. efsane "Das Erdmännlein und der Schäferjung" (Mirket ve Delikanlı Çoban) adlı efsanedir (bkz. Grimm 1912).

Grimm Kardeşlerin efsanelerinde olduğu gibi masallarında da çoban ve çobanlık konuları işlenmiştir. Sevgili Roland, Köpek ve Serçe, Küçük Çoban, Kaz Çobanı ve Çeşmedeki Kaz Çobanı masalları (bkz. Grimm 2012) örnek verilebilir.

\section{Barok Döneminde Çoban Edebiyatı}

Çoban kültürünün Alman Edebiyatında tarihinde XVI. ve XVII. yüzyılda ağırlık kazandığı görülür. Çobanları konu edinen romanlar "Schäferroman" (Çoban Romanı), şiirler ise "Schäferlyrik" (Çoban Şiiri) olarak adlandırılır. Bu edebi türlerin yaygın olduğu dönem Avrupa'da mezhep savaşlarının yaşandığı, açlık ve sefaletin kol gezdiği Barok (1600-1720) dönemidir. Yazar ve şairlerin neden Çoban Edebiyatına yöneldiklerini anlayabilmek için bu dönemin sosyal, politik ve dini yönünün ayrıntılarını ele almak faydalı olacaktır.

Barok döneminin en belirleyici olayı Otuz Y1l Savaşları'dır. Otuz Y1l Savaşlarının nedeni Katolikler ve Protestanlar arasındaki din kökenli mezhep çatışmalarıdır. Savaşlar hem Avrupa'da hem de Almanya'da toplum psikolojisi açısından oldukça etkili olmuştur. $\mathrm{Bu}$ dönem çiçek, kolera, tifo, veba gibi bulaşıcı hastalıkların oldukça yaygın olduğu, Alman nüfusunun yaklaşık üçte birinin hayatını kaybettiği yıllardır. Tüm bunların yanında Alman toplumunda salgın hastalıklarla beraber ölüm korkusu, karamsarlık ve açlık korkusunun üst seviyelerde hissedildiği dönemdir.

Bu dönemde Almanya siyasi açıdan federal devletlerden oluşmaktadır. Yaklaşık üç yüz küçük prensliğin egemenliği söz konusudur. İmparatorluktaki küçük prensliklerin her biri birer bağımsız devlet konumundadır. Avrupa'da 1618 yılında başlayan Otuz Yıl Savaşlarının ardından sağlanan barış süreciyle bu durum 1648'de Vestfalya Barışı ile sonlanmış, antlaşma ile Kalvenizm mezhebi herkes tarafından kabul edilmiştir. 
$\mathrm{Bu}$ antlaşmaya göre imparator savaş ilan edemeyecek, vergi ve asker toplayamayacaktır. Böylece imparator pasivize edilerek yetkilerinin birçoğu elinden alınmıştır. Otuz Y1l Savaşları sonrasında kazananlar imparatorlar değil, taşra prensleri olmuştur. Fransız yazar Voltaire'in (1694-1778): "Dieser Korpus, der sich immer noch Heiliges Römisches Reich nennt, ist in keiner Weise heilig, noch römisch, noch ein Reich" (Roma İmparatorluğu artık hiçbir şekilde ne kutsal Romalı, ne de imparatorluktur) sözleri bu durumu özetler (Ute van Runset 1996: 57).

Yine bu dönemde İspanya, Hollanda'nın bağımsızlığını tanımış, iki ülke arasında süren Seksen Yıl Savaşları barışla sonuçlanmıştır. Milli birliğin sağlanamaması, genel olarak Orta Avrupa'da gücün parçalanmasına neden olmuştur. Ayrıca yaşanan tüm bu olaylara paralel olarak XIV. Louis'nin (1638-1715) hegemonik savaşları, tüm Avrupa'yı etkilemiştir. Dönemin önemli olaylarından biri de katı bir Katolik olan Fransız Kralı XIV. Louis'nin Kalvenist Fransız vatandaşlarını sürgüne göndermesidir. Dini inançlarından dolayı baskı gören Protestan Fransızlar Berlin'e göç etmek zorunda kalırlar. Avrupa'da yaşanan tüm bu olumsuzluklara İsveç ve Türk savaşlarını da dâhil etmek gerekir.

Barok insanı yaşanan tüm bu olumsuzluklardan dolayı ruhen çöküntü halindedir; yaşadığı bunalım sebebiyle ölüme yakınlık duymaktadır. XI. Yüzyılda kurulan Cluny tarikatı halkı olumsuz yönde etkilemiş, "Memento mori" (Ölümü hatırla) söylemiyle ölümün soluğunu sürekli enselerinde hissetmelerine neden olmuştur (Nakiboğlu 2010b: $53)$.

Barok döneminde olduğu gibi XI. yüzyılda da Alman halkına her an ölecekmişlik duygusu hâkimdir. XI. yüzyıldaki ölüm düşüncesi tamamen dini inanç gereği ölüm sonrası hayata tutunmanın, bu dünyayı yok saymanın ve münzevi yaşamanın sonucunda oluşmuştur. Oysa Alman halkının Barok döneminde kendisini ölüme yakın hissetmesi karşılaştığı sıkıntılardan, yaşanan mezhep savaşlarının dehşetinden kaynaklanmaktadır. Savaşın insanlarda oluşturduğu tüm negatif düşünceler Barok insanına sürekli bu dünyanın faniliğini anımsatır.

Öte yandan bu dönem insanında olumsuz tüm bu düşüncelerin zıddı olarak yaşanılan hayattan keyif alma (Lebesgenuss) ve tutkular görülür. Söz konusu bu durum Barok'un Carpe diem (Nütze den Tag/Pflücke den Tag!) "Hayatın tadını çıkar/Gününü gün et!" felsefesine dayanır.

Barok döneminde çoban edebiyatı önemli bir misyon üstlenmiştir. Yaşama sevincini yitirmişlerin umut 1şığı olur. Sürekli ölümü düşünen karamsar insanlara yeni bir pencere açarak mutlu olmaları sağlanmıştır. Çoban şiirleri, çoban oyun ve türküleri bir nevi halkın yaşama sevinci, neşe kaynağı olmuştur.

\section{Pastoral Romanın Tarihçesi}

Pastoral romanların arka planında antik Yunan kültür ve mitolojisi etkindir. Arzu edilen hayat için gerekli ideal özellikler doğayla betimlenmiştir. Özellikle savaşın etkilerinden kurtulmak amaciyla huzur ve mutluluk kaynağı olan doğa tercih edilmiştir. 
Pastoral roman türünün öncüsü Latin şairi Virgil'in Bucolica'sıdır (Yaklaşık M.Ö. 40). Eser pastoral Arcadian şiir geleneğinden gelir. İtalyan hümanist şairler Francesco Petrarch (1320-1323) ve Giovanni Boccaccio (1333-1375) ile XIV. yüzyılda lirik pastoral şiir gelişir.

Pastoral roman daha sonraları düzyazı biçiminde İspanyol Barok döneminde başarılı bir tür haline gelir. Avrupa'da ise Rönesans'la başlayıp, Barok ile devam eder (bkz. Garber 1985: 1-22). Bu roman türü her şeyden önce doğaya yakınlığı, ülkelerin idil hayatının sadeliğini/güzelliğini ve doğaya özlemi konu edinir. Eserlerde barışın olmadığı dünyada en azından şiirle de olsa doğa özlemi giderilmeye çalışılır.

Pastoral roman Barok döneminde daha çok taşra aristokratları ve üst düzey sınıf için yazılmıştır. Asillerin eğlencesini ve sosyal realiteden kaçışı yansıtır (Nakiboğlu 2010b: 54).

Alman saray romanları Avrupa Rönesans'ının pastoral saray romanlarından farklı olarak, fazla siyasi yetkisi olmayan taşra aristokratlarını ve yeni oluşmaya başlayan orta sınıfı kapsar (Niefanger 2006: 211). Romanlarda tanınmış kişiler çoban kıyafetli ve maskelidir; söz konusu bu tarz o dönemin modasıdır. Bazı durumlarda prenslerin lehinde ya da aleyhinde eleştiriler de yer alır.

Pastoral roman biçimsel olarak birçok paralel öyküden oluşur. Romanlarda içeriğe dâhil edilen hikâyeler çeşitli alegorik öğelerle biçimlendirilmiştir. Zaman zaman lirik bölümler de esere serpiştirilmiştir. Doğa olduğundan daha abartılıdır; genellikle de çoban çiftlerin aşklarını anlatır.

Arcadia, İtalyan şair Jacopo Sannazaro'nun pastoral şiiridir. 1480-1484 yılları arasında yazılmıştır. İlk olarak 1502'de, ikincisi de 1504'te yayımlanmıştır. Nesirle başlar, on iki küçük idil şiirle devam eder. Eser şairin aşklarını konu edinir. Bu eser, Avrupa Barok edebiyatını etkileyen başyapıtlar arasındadır.

Portekizli yazar Jorge de Montemayors'un Diana (1559) adlı pastoral eseri de Avrupa genelinde etkili olmuştur. Gelişmiş İspanyol geleneğinin diğer önemli metinleri Lope de Vegas'in Arcadia (1598) ve Miguel de Cervantes'in La Galatea'sıdır (1585). Eserde pastoral karakterlerin kisvesi altında aşk konuları işlenmiştir.

Edebi tür olarak öncelikle Büyük Britanya'da Sir Philpp Sydney'in (15541586) Arcadia (1581) adlı eseri yayınlanır. Sydney bu eserinde İspanyolları örnek alır. $\mathrm{Bu}$ eser Barok dönemi şairi Martin Opitz (1597-1639) tarafından Almancaya çevrilir. İtalya'da Barclay'ın (1582-1621) Argensis (1621) isimli yapıtı yayınlanır. Fransa'da roman yazarı Honoréd'Urfé'nin (1567-1625) beş perdelik L'Astrée (1607-1627) adlı eseri tüm Avrupa'yı etkileyerek birçok dile çevrilir. Eserin son bölümünün, Honoréd'Urfé'nin sekreteri T. Baro tarafından derlendiği tahmin edilir (Nakiboğlu 2010b: 54). Bu eser de 1619'da Almancaya tercüme edilerek Alman Literatürüne kazandırılır. Dolayısıyla pastoral roman Almanya'da diğer Avrupa ülkelerine kıyasla daha geç başlar. Özellikle Opitz ve şair/çevirmen Georg Philippe Harsdörffer'in (16071658) gayretli çevirileri ve düzenlemeleriyle Alman Edebiyatına girer. 
Görüldüğü gibi Pastoral roman Alman Edebiyatı için yabancı kaynaklıdır. Çeviriler yoluyla girerek gelişim göstermiştir. Bu türdeki ilk önemli orijinal eser Barok dönemi yazarlarından Opitz'in Schäfferey von der Nimfen Hercinie (1630) adlı eseridir. Pastoral romanlar genellikle mitolojik bir mekân olan Arkadia'da geçer; oysa Opitz'in bu eseri halk tarafından bilinen/tanınan Alman bölgesinde geçer (Nakiboğlu 2010b: 54).

Eser, daha çok şairin hayalini kurduğu dağlık bir arazideki geziyi anlatır. Pastoral özellikleriyle dikkat çeken eserde ünlü Rüberzahl (1561) efsanesi de geçmektedir. Şair ve arkadaşının kahraman olarak ele alındığı bir çoban şiiridir. Daha sonra çoban şiiri denilen bu lirik türe erotiklik ve oyun unsurları da katılmıştır (Aytaç 2011: 37). Esere konu olan şair ve arkadaş1, çoban olarak tasvir edilmiştir. Hikayede şiir ve dram sahneleri bir arada kullanılmıştır.

Bir başka roman ise Philipp von Zezen'in (1619-1689) Die Adriatische Rosemund (1645) eseridir.

Pastoral roman türü ile pastoral şiir arasında benzerlikler söz konusudur. Pastoral roman türü, ortaya çıktığı ve şekillendiği dönem nedeniyle "Barok romanı" olarak adlandırılmıştır (Nakiboğlu 2010b: 54). III. yüzyılda Longos von Lesbos Daphnis ve Chole adlı çoban romanını yazmıştır. Romanın konusunu yaban hayatına terkedilmiş iki çocuğun çobanlarca sahiplenilerek büyütülmesi, çocukların birbirlerine olan sevgileri anlatılmaktadır. Eser XVI. ve XVII. yüzyılda çoban edebiyatı alanında tüm Avrupa'yı etkilemiştir.

\section{Pastoral Eserlerin Özellikleri}

Pastoral roman ve pastoral şiirler kadın/erkek çobanların birbirlerine olan aşk ve maceralarını konu edinir. Eserlerde çılgıncasına yaşanan aşklar ve çoğunlukla hüzünle biten ayrılışlar görülür. Pastoral romanlar kişisel bir yaklaşımı benimser ve ailevi konuların yerine öncelikle politik olmayan aşk hikayelerini konu edinir.

Pastoral eserlerde dikkat çeken bir başka özellik ise doğanın dört mevsim yeşil olmasıdır. Hiçbir zaman tabii afet ve firtınalar olmaz, çimler sürekli bol ve yemyeşildir (Nakiboğlu 2010b: 55). Doğada her şey, her zaman, iyi ve güzeldir. İdeal doğa tasvirleri dikkat çeker. Metinsel sürece özel ve açık bir şekilde vurgu yapılırken, yüksek ve düşük roman arasında bir ara konum içerir (Niefanger 2006: 211).

Bazı pastoral romanlar ise kırılgan, sevgilisi tarfından terkedilmiş, acı çeken, duyguları reddedilen kadın çobanları konu edinmiştir. Geçmişte yaşanan güzel, mutlu günler, kaybolan değer yargıları, vatan özlemi işlenen konular arasındadır.

Pastoral romanlarda genellikle erkek hâkimiyeti görülür. Kadının evlendikten sonra eşine hizmet etmesi çobanlarca beklenen bir davranış biçimidir. Kadının eşinin emirlerini yerine getirmemesi, itaatsizliği sosyal çevre tarafından dişlanmasına neden olur. Eserlerde pasif kadın karakterler aktif çobanlar tarafından betimlenir ve kadınlar her zaman pasiftir. 
Eserler daha çok içerdikleri lirik ve müzikal unsurlar açısından dikkat çeker. Ayrıca nesir diyaloglar ve sanatsal beyitlerden oluşmaktadır. Eserlerde geleneksel çoban hayatı idealleştirilmiştir.

Arkadik ve Bukoliktik kavramları Schäfer ve Hirtendichtung şeklinde eş anlamlarıyla kullanılmıştır. Çoban literatürünün kaynağı çobanların söyledikleri geleneksel Arkadik şiirlerdir.

Opitz, İtalyan librettist Ottavio Rinuccini'nin (1562-1621) çoban operas1 Daphne'yi döneminin önde gelen bestecilerinden Heinrich Schütz'a (1585-1672) iletir. Schütz'ün bestelediği müzikle ilk Alman operası (1627) sahnelenir. Çoban romanı opera ve şarkılı komedilere girmesiyle yaygınlaşır. Popülaritesi burjuva çevrelerinde giderek daha da artar. Tür gelişiminde ise en geç XIX. yüzyılda pastoral ülke ve köylü romanı adıyla yer alır.

Çoban kültürü resim sanatını da kapsamaktadır. Bu konuda Fransız ressam William Adolphe Bouguereau'nun (1825-1905) resimleri örnek gösterilebilir.

Dramatik saray çoban oyunları İtalyan Francesco de' Rossi'nin (1510-1563) Torquato Tassos Aminta eseri ile başlar. Bu eseri Giovanni Battista Guarini'nin (15381612) II Papazı Fido adlı eseri takip eder ve tüm Avrupa dillerine çevrilir. Alman Edebiyatına Der getreue Schäfer (Sadık Çoban) olarak kazandırılır.

Alman Barok yazarı/şairi Andreas Gryphius'un (1616-1664) Das verliebte Gespenst: Die geliebten Dornrose (Âşık Hortlak: Sevgili Dornrose) (1660) adlı eseri Alman literatüründe önemli pastoral eserlerden biridir. Das verliebte Gespenst'in konusu Cardenia Celinde'nin komedi tarzında ele alınışına benzer. Die geliebten Dornrose eseri ise bir köy komedisidir. İki aile arasında yaşanan ezeli düşmanlık ve bu ailelerin çocukları arasında geçen aşk komedi tarzında işlenir. Her iki oyunun ortak yanı, sadakatli aşkın gücünü gösterir (Aytaç 2020: 40-41).

Diğer çoban oyunlarına, Heinrich Elmenhorst'un (1632-1704) Das Kätzgen (1746), Die Kirrns (1746), Das Strumpfband(1748); Adam Gottfried Uhlich'in (1718-1753) Rosetta (1653), Das Fest (1742), Neue Lustspiele (1746/48); Johann Sigismund Scholze'nin (1705-1750) Das Kätzgen, (1746) Die Kirmes (1746); Christian Nicolaus Naumann'ın (1720-1797) Die Martinsgans (1746); Karl Christian Gärtner'in (1712-1791) Die geprüfte Treue (1774) ve J.W. von Goethe'nin (1749-1832) çoban oyunları tarzında Die Laune des Verliebten (1768) adlı eserler örnek olarak verilebilir. 


\section{Pastoral Aşk Türküleri (Madrigaller)}

Madrigal $^{3}$ kelimesinin kökeni İtalyanca "Madriale" kelimesinden türemiştir ve aşk türküleri anlamına gelmektedir. $\mathrm{Bu}$ eserlerin kaynağı çobanlar ve onlar tarafından söylenen aşk türküleridir.

Madrigaller kısa ve idil türkülerdir. Rönesans ve Barok dönemlerinde söylenmeye başlanmış, dini olmayan, vokal müzik eşliğinde seslendirilen çoksesli türkülerdir. İki ile sekiz ses arasında değişmekle birlikte, genellikle üç ya da altı sesli olarak, çalgı aleti olmadan da seslendirilir. XIV. yüzyıldan itibaren İtalya'da söylenegelmektedir. Lirik şairleri olarak soneleriyle tanınan İtalyan Francesco Petrarca (1304-1374), Gianni Sacchetti (1330-1400) ve Donati sayılabilir (Nakiboğlu 2010b: $56)$.

Madrigallerde dil ve müzik kurallarına uyulmamıştır; genellikle 8-11 hecelidir. XVI. yüzyıldan itibaren 7 heceli, serbest sıralı, kafiyesiz, serbest tarzı yaygındır ve 15 madrigolan şeklinde adlandırılmaktadır (Wilpert 1979: 487).

XVI. yüzyılda madrigallere katı kurallar getirilmiştir. Üçlü triolar bitişik 2 kafiyeli misralar şeklinde devam eder. Bunlar $a b b, c d d$, eff, $g g, h h$ şeklindedir. İtalya' da ilk söylenmeye başlandığı dönemlerde müziksiz söylenmiş, XVI. ve XVII. yüzyıllarda kapsamı genişletilerek hicvedici/esprili konulara değinilerek müzikal komedilerle devam ettirilmiştir. Fransa'da Barok döneminde söylenmeye başlanmıştır.

Bir başka müzik türü 1470-1530 yılları arasında zirveye ulaşan Frottola 'lardır ${ }^{4}$. İtalyanca yazılan şiirlere ilginin artmasıyla etkini artırmıştır (Nakiboğlu 2010b: 57). Madrigaller Batı müziğinde Orta Çağın sonlarından başlayarak günümüze ulaşmış farklı vokal müzikal besteleri olan Motet'lerde ${ }^{5}$ de etkili olmuştur.

Madrigallerin gelişimi XVI. yüzyılın ikinci yarısında zirveye ulaşmış, XVII. yüzyılın başlarında solo şarkıların gelişimiyle önemini yitirmeye başlamıştır. Müzik eşliğinde icra edilen, çoğunlukla birden fazla bölüm içeren sözlü bestelerden oluşan Cantata ve Diyalog ile birleşen Madrigal operanın gelişimiyle yerini Arya 'ya ${ }^{6}$ bırakmış (bkz. Ziegler 2015) akabinde müzikal bale ve korolar yaygınlaşmıştır.

Barok döneminin önemli pastoral şiir yazarları arasında, daha önce de değindiğimiz gibi Martin Opitz, August Ausburger (1726-1722), Johann Joseph Beckh (1635-1692), Paul Fleming (1609-1640), Enoch Gläser (1628-1668), Jacob Schwieger

\footnotetext{
${ }^{3}$ Madrigal: Orta Çağın sonları, Rönesans ve Barok dönemlerini kapsayan, genellikle dini olmayan vokal müzik kompozisyonudur. Çok sesli olarak söylenir, iki-sekiz arasında değişen düzenlemeleri vardır. Geleneksel olarak enstrümansiz seslendirilir.

4 Frottola: 15. YY'da orta ve kuzey İtalya'da, özellikle Floransa'da, karnavallarda yaygınlaşan, 1530'larda Madrigal'in çıkışı ile önemini yitirmiş dans ezgisi Ballata'dan kaynaklanan neşeli ve çok dizeli dans şarkısıdır.

${ }^{5}$ Motet: Orta Çağın sonlarından günümüze kadar çok çeşitli şekil ve stile sahip, bir vokal müzikal kompozisyondur.

${ }^{6}$ Arya: Operada orkestra eşliğinde solistin söylediği, genellikle de kendi içinde bütünlük sağlayan şarkıdır.
} 
(1629-1663), Friedrich Spee von Lanngenfeld (1591-1635), Philipp von Zezen (16191689), Andrea Gryphius yer alır.

Gryphius tarafından 1663'te yazılan Es ist alles Eitel/Her Şey Boş adlı şiiri Barok dönemi insanının ruh dünyasını yansıtması açısından önemlidir. Şiirin genelinde Barok döneminde sıkça konu edinilen "Vergänlichkeit/fanilik" motifi işlenmiştir. İnsanların hiçliği, bu dünyada inşa ettiklerinin geçiciliğine vurgu yapılarak, doğada hiçbir şeyin kalıcı olmadığı üzerinde durulmuştur. Ölüm sonrası sonsuzluk umulur. Gryphius'un Es ist alles eitel adlı şiirinden bir dörtlük:

\footnotetext{
Du siehst, wohin du siehst, nur Eitelkeit auf Erden,

Was dieser heute baut, reißt jener morgen ein;

Wo itzund Städte stehn, wird eine Wiesen sein,

Auf der ein Schäferskind wird spielen mit den Herden (Gryphius 1637)
}

Çoban edebiyatının zirvede olduğu dönemde Nürnberg'li Pegnesichen Blumenordern grubu şairleri arasında Georg Philipp Harsdörffer (1607-1658), Johann Klaj (16161656) ve Sigmund von Birken (1626-1681) yer alır. Harsdörffer Nürgberg'de 1644 'de Pegnitzschhäfer adlı dil cemiyetini kurar. O dönemde dil cemiyetleri aynı zamanda tercüme ve poetik çalışmalarla birçok eseri Alman Edebiyatına kazandırmıştır.

Alman çoban edebiyatının saray şairleri diğer Avrupalı öncülerin tam aksine hedef kitlesi olarak halkı seçmiştir. Böylelikle sosyal ve tarihi bakış açısının doğmasını sağlamışlardır. Gürsel Aytaç'a göre Rokoko çoban şiirlerinde dinlendirici bir doğa, sorumluluk yüklenmeyen aşk oyunları ve rahat bir dünya söz konusudur.

$\mathrm{Bu}$ şiirlerin günlük burjuva hayatını dengeleyen bir kaçış alanı olduğu söylenebilir. Ahlak ve din konularıyla düzenlenmiş burjuva hayatında eğlenceye pek yer yoktur. Gerçek hayatta özlem duyulan konular Rokoko şiirleriyle giderilmiştir (Aytaç 2001: 71).

Madrigaller Alman Edebiyatına Barok döneminde girmiş, Barok şiiriyle bağlantılı olarak zirveye çıkmıştır. Barok döneminde etkili olduğu gibi Anekreontik ve Romantik döneminin şairlerini de etkilemiştir. Barok döneminde Andreas Gryphius, Philipp von Zesen, Aydınlanma döneminde Christop Martin Wieland (1733-1813) ve Johann Peter (1733-1796) önemli çoban şiirlerini kaleme almışlardır.

Daha sonraları Anekreontik'in bazı özellikleri Rokoko döneminde tekrar ortaya çıkarak XIX. yüzyılda idil hayata geçilmiştir. Anekreontik şairler ve romantikler tarafindan taklit edilmiştir. Bu alanda önde gelen isimler, Friedrich von Hagedorn (1708-1754), Götz von Berlichingen (1480-1562), Friedrich Wilhelm Gotter (17461797), Christian Fürchtegott Gellert (1715- 1769), Johann Heinrich Voss (1751-1826) ve Goethe'dir (1749-1832). Goethe, Leibzig Madrigalleri, Müzikal Komedi ve Faust I'i yazmıştır. Konusu aşk olan Annette adlı Madrigalini örnek vermek istiyoruz. 


\author{
Mein Mädchen, sagte mir: Wie schön \\ Ist nicht Olind! ich hab' ihn heut gesehn, \\ Lang sah ich ihn bewundernd an; \\ Wer hätt' ihn nicht bewundern sollen? \\ Geliebter, du wirst doch nicht schmollen, \\ Daß ich's getahn? \\ Ich sprach: Mein Herz fühlt nichts vom Neide, \\ Was auch dein Mund für Lob der Schönheit giebt; \\ Denn liebtest du die schönen Leute, \\ Sprich, hättest du mich je geliebt? (Goethe 1767: 94-94)
}

\title{
Sonuç
}

Çobanlık dünyanın en eski mesleklerinden birisidir. Bu sebeple çobanlık mesleğinin milletlerin yazılı ve sözlü edebiyatlarında hemen hemen her dönem etkili olduğu görülmüştür. Yunan mitolojisinde çobanların koruyucu Tanrısı Pan'dır. Pan diğer mitolojik Tanrıların arasına kabul edilmemiş, bu nedenle de hayatını Arkadya olarak bilinen İdil ovalarda sürdürmüştür. Tüm edebi türlerde mekân mitolojide olduğu gibi Arkadya'da geçtiği görülmüştür. Çobanlık mesleğinin mitolojide konu edildiği gibi kutsal dinlerde de önemli olduğu tespit edilmiştir.

Pastoral eserlerin Avrupa'da Rönesans döneminde şiirlerle başladığ görülmüştür. Bu akımın öncü türü İtalyan Vergils Bucolica'dur. Avrupa'daki pastoral romanın öncüsü ise Jacopo Sanazzaro'dur. Eser, Avrupa edebiyatında pastoral doğayı temsil eden Arcadia temasını başlatmıştır. Bu akımın önce İtalya'da başladığı, daha sonra İngiliz ve Fransız edebiyatında etkili olduğu görülmüştür. Almancaya çeviriler yoluyla kazandırılmıştır. Almanya'da daha çok Barok döneminde ilgi uyandırdığı ve eserler verildiği tespit edilmiştir. Geçmişi ve gelişim süreci incelendiğinde çobanlık kültürüne ve saray çoban edebiyatına dayandığı görülmüştür.

Çoban edebiyatı Alman literatüründe efsane, menkıbe, atasözü ve masallara konu olmuştur. Barok döneminde birçok Alman yazar ve şaire ilham kaynağı olmuş, çoban romanları, çoban şiirleri yazılmıştır. Özellikle Otuz Yıl Savaşları'nın yaşandı̆̆ı Almanya'da etkili olmuştur. Dönemin buhranlı ortamından kurtulmak için pastoral eserlerle rahatlama (katharsis) sağlanmaya çalışılmıştır.

Alman literatüründe Barok döneminde tanınmış yazarların eserleri olduğu gibi daha sonraki dönemlerde farklı türlerde de eserlerin olduğu tespit edilmiştir. Müzik alanında da Madrigallerle etkili olmuş, bale ve korolarda yaygın bir şekilde söylenmiştir. Çoban oyunlarının operanın oluşumunda etkili olduğu görülmüştür.

Literatur taramalarımız esnasında ülkemizde Avrupa ve Almanya'da Barok dönemi Çoban Edebiyatını konu edinen herhangi bir çalışmaya rastlanmamıştır. Söz 
konusu durum dikkate alınırsa bu makalenin bir ilki oluşturacağı ve bu alanda yeni çalışacaklara yol göstermesi açısından önemlidir.

\section{Kaynakça}

Aytaç, Gürsel (2001): Yeni Alman Edebiyatı Tarihi. İstanbul: Multi Lingual.

Garber, Klaus (1985): Formen pastoralen Erzählens im frühneuzeitlichen Europa. Internationales Archiv für Sozialgeschichte der deutschen Literatur 10.

Goethe, Johann Wolfgang von (1767): Annette. Leibzig: Faksimile-Neudruck der Ausgabe Leipzig. Frankfurt a.M.: Insel-Verlag.

Grimm, Jacob/ Grimm, Wilhelm (1912): Deutsche Sagen, 1.-2. Band, Wien-Leibzig: Gerlach Wiedling.

Grimm, Jacob/ Grimm, Wilhelm (2012): Grimm Masalları. (K. Şipal, Çev.) İstanbul: Yapı Kredi Yayınları.

Gryphius, Andreas (1637): “Es ist alles Eitel" http://www.rhetoriksturm.de/es-ist-alles-eitelgryphius.php (Alıntılama Tarihi: 01.03.2020).

Hinrichs, Ernst / Krebs, Roland / Runset, Ute van (1996): »Pardon, mon cher Voltaire ...« Drei Essays zu Voltaire in Deutschland. Göttingen: Wallstein Verlag.

Nakiboğlu, Meryem (2010a): Des Meeres und der liebe Wellen. V. Uluslararası Van Gölü Havzası Sетроzуити. Van: Van Valiliği Basımı. 273-281.

Nakiboğlu, Meryem (2010b): 17.Y.Y. Barock Dönemi Alman Edebiyatında Çoban Kültürü. Yüzüncü Yıl Üniversitesi Sosyal Bilimler Enstitüsü Dergisi, 51-59.

Naumann, Friederike (1983): Ikonographie der Kybele in der phrygischen und der griechischen Kunst. Tübingen: Wasmuth.

Niefanger, Dirk (2006): Barock: Lehrbuch Germanistik, 2. Auflage, Stuttgart: Springer Verlag.

Nilsson, Martin P. (1992): Geschichte der griechischen Religion. München: C.H.Beck.

Şahin, İlhan (2018): Göçebe Uygarlı̆̆ında "Çoban" ve "Çobanlık". Uluslararası Çoban Mustafa Paşa ve Kocaeli Tarihi-Kültürü Sempozyumu-IV Bildirileri, I . Kocaeli: Kocaeli Büyükşehir Belediyesi. 107-115.

Wander, Friedrich Wilhelm (1873): Deutsches Sprichwörter-Lexikon (Band 3). Leipzig: Brockhaus.

Wilpert, Gero von (1979): Sachwörterbuch der Literatur. Stuttgart: Alfred Kröner Verlag.

Ziegler, Christiana Mariana (2015): Versuch in gebundener Schreib-Art . Berlin: Karl-Maria Guth. 